J. Clin. Chem. Clin. Biochem.

Vol. 17, 1979, pp. 581-585.

\title{
Comparison of Four Commercially Available cAMP Kits
}

\author{
By J. Vossenberg, G. Mulder, J. Thijssen, \\ Department of Endocrinology, Academic Hospital Utrecht,
}

\author{
P. Bruynzeel, M. Hamelink and J. Kreukniet, \\ Department of Pulmonary Disease, Academic Hospital Utrecht, State University, Utrecht, The Netherlands
}

(Received September 11, 1978/February 8, 1979)

Summary: In this study four commercially available cAMP kits were compared and shown to differ with respect to reliability, sensitivity, simplicity and expiration time.

It is not possible to recommend a particular kit, because the choice depends on the demands of the investigator, which, of course, may vary. However, in our opinion, one of the kits was inferior to the others.

\section{Vergleich von vier kommerziell erhältlichen cAMP-Kits}

Zusammenfassung: In dieser Studie werden vier kommerziell verfügbare cAMP-Kits verglichen. Zuverlässigkeit, Sensitivität, Simplizität und Haltbarkeit wurden untersucht und Unterschiede festgestellt.

Es ist nicht möglich, einen speziellen Kit zu empfehlen, weil die Wahl abhängig ist von den Anforderungen des Untersuchers, die selbstverständlich verschieden sind. Unserer Meinung nach jedoch war einer der Kits minderwertig.

\section{Introduction}

Since Sutherland \& Rall discovered cAMP in 1958 (1), many investigations have been carried out on the biological role of this substance (2).

For the determination of CAMP a competitive protein binding assay has been developed by Gilman (3) and a radioimmunoassay by Steiner et al (4). Both techniques have been commercially adapted.

The results of the comparison of four commercially kits are reported. Of these kits three were competitive protein binding assays and one a radioimmunoassay. These kits have been compared with respect to reliability, sensitivity, simplicity and expiration time.

\section{Materials and Methods}

\section{Reagents}

The following kits were used: Amersham (The Radiochemical Centre, Amersham, Buckinghamshire, U.K.), Diagnostic Products (Diagnostic Products Corporation, Los Angeles, Ca., U.S.A.), Boehringer (Bóhringer, Mannheim GmbH, Germany) and Schwarz-Mann (Becton, Dickinson and Company, New York, N.Y., U.S.A.) $)^{1}$ ).

1) In the text the following abbreviations are used: Amersham = A, Diagnostic Products $=\mathrm{B}$, Boehringer $=\mathrm{C}$, Schwarz-Mann $=\mathrm{D}$.
The following chemicals were used: trichloroacetic acid p.a., tris-(hydroxymethyl)-aminomethane p.a. and magnesium chloride $\left(\mathrm{MgCl}_{2} .6 \mathrm{H}_{2} \mathrm{O}\right)$ p.a. from Merck (Darmstadt, Germany), diethyl ether and hydrochloric acid $(\mathrm{HCl})$ from British Drug Houses (Poole, U.K.), $\beta$-mercaptoethanol p.a. and Dowex $1 \times 2$ $100 / 200$ mesh from Fluka (Buchs, Switzerland). Phosphodiesterase (from beef heart in $500 \mathrm{~g} / \mathrm{l}$ glycerol) was obtained from Boehringer (Mannheim GmbH, Germany), Instagel (scintillation liquid for aqueous and non-aqueous samples) from Packard (Downer's Grove, Ill., U.S.A.), Ficoll-Paque from Pharmacia Fine Chemicals (Uppsala, Sweden) and isoproterenol from Sigma (St. Louis, Mo., U.S.A.).

[8- $\left.{ }^{3} \mathrm{H}\right]$ adenosine $3^{\prime}, 5^{\prime}$-cyclic phosphate, ammonium salt (batch 22 , specific activity/1.0 PBq/mol) was obtained from the Radiochemical Centre (Amersham, Buckinghamshire, U.K.). Before use its purity was checked by paper chromatography (5).

\section{Procedure}

Preparation of extracts

Lymphocytes were isolated according to a slightly modified procedure of Bфyum (6) on a ficoll gradient (purity of lymphocytes obtained $95 \%$ ). Stimulation of the cAMP content of the lymphocytes was carried out as described by Gillespie et al (7). The extracts LO, L5, L4, L4', L3 were stimulated with 0,10 , $100,1000 \mu \mathrm{mol} / 1$ isoproterenol respectively.

Mammary cancer tissue was obtained during surgery. After freezing in liquid nitrogen the tissue was homogenized with a microdismembrator (B. Braun, Melsungen).

Urine was diluted 1:100 with demineralized water.

Extraction of CAMP from the lymphocytes and mammary cancer tissue was performed as described by Gilman (8). The diluted urine was used directly in the assay. 
To correct for losses during extraction and purification $\left[{ }^{3} \mathrm{H}\right]$ cAMP was added as an internal standard.

\section{Purification of the extracts}

The extracts were purified over a Dowex $1 \times 2$ column as described by Mao \& Guidotti (9). By this procedure cAMP is separated from cGMP.

\section{Phosphodiesterase test}

The phosphodiesterase test was performed with some minor modifications as described in the protocol of kit $\mathrm{C}$.

\section{Determination of CAMP}

The experimental setting of the assays of the different kits is scheduled in table 1 (method of determination, incubation, separation, counting system and comments). Computation of the CAMP values was performed according to the instructions enclosed by the manufacturers.

\section{Results}

First the purification procedure by Dowex $1 \times 2$ column chromatography was examined. The radioactive elution pattern obtained by applying a mixture of $\left[{ }^{14} \mathrm{C}\right] \mathrm{cAMP}$ and $\left[{ }^{3} \mathrm{H}\right]$-cGMP was identical to that reported by Mao (9).

In seven different extracts the cAMP contents were measured with the four cAMP kits before and after purification. The results of these measurements are shown in figure 1.

From this figure it can be seen that the kits $C$ and $D$ tend to give higher values after the purification procedure. In addition the values measured with these two kits are somewhat higher than those obtained with kit A and B.
Furthermore kit B seems relatively insensitive for substances eliminated by the purification procedure.

In figure 2 the results are presented of the recovery of pure cAMP added to the extracts. For these studies the standard preparations provided with the kits were used The results of the addition experiments, carried out in both unpurified and purified extracts, are expressed as $\triangle \mathrm{cAMP}$ measured/ $\triangle \mathrm{cAMP}$ added; which ideally should be unity (figure 2). Furthermore two-fold concentration experiments were performed (once again before and after purification). The results of these tests are presented as the ratio of the cAMP content of the double versus the single concentration (fig. 3 ).

From figure 2 it is evident, that the values measured tend to scatter less after purification. With all kits tested the points after purification concentrate around 1.00. Moreover the deviation in the measurements is decreased after purification. In unpurified extracts, kit $\mathrm{C}$, and to a lesser extent kit $D$, give an underestimation of the amount of pure cAMP added. This is in accordance with figure 1 in which kit $C$ and kit $D$ show a considerable rise in measured cAMP concentrations after purification. In our opinion the data of the two-fold concentration experiments give less information; it is remarkable that even after purification kit $\mathrm{C}$ gives ratios which remain smaller than 2.00 . This may be caused by the fact that in the low concentration range kit $\mathrm{C}$ overestimates the cAMP contents.
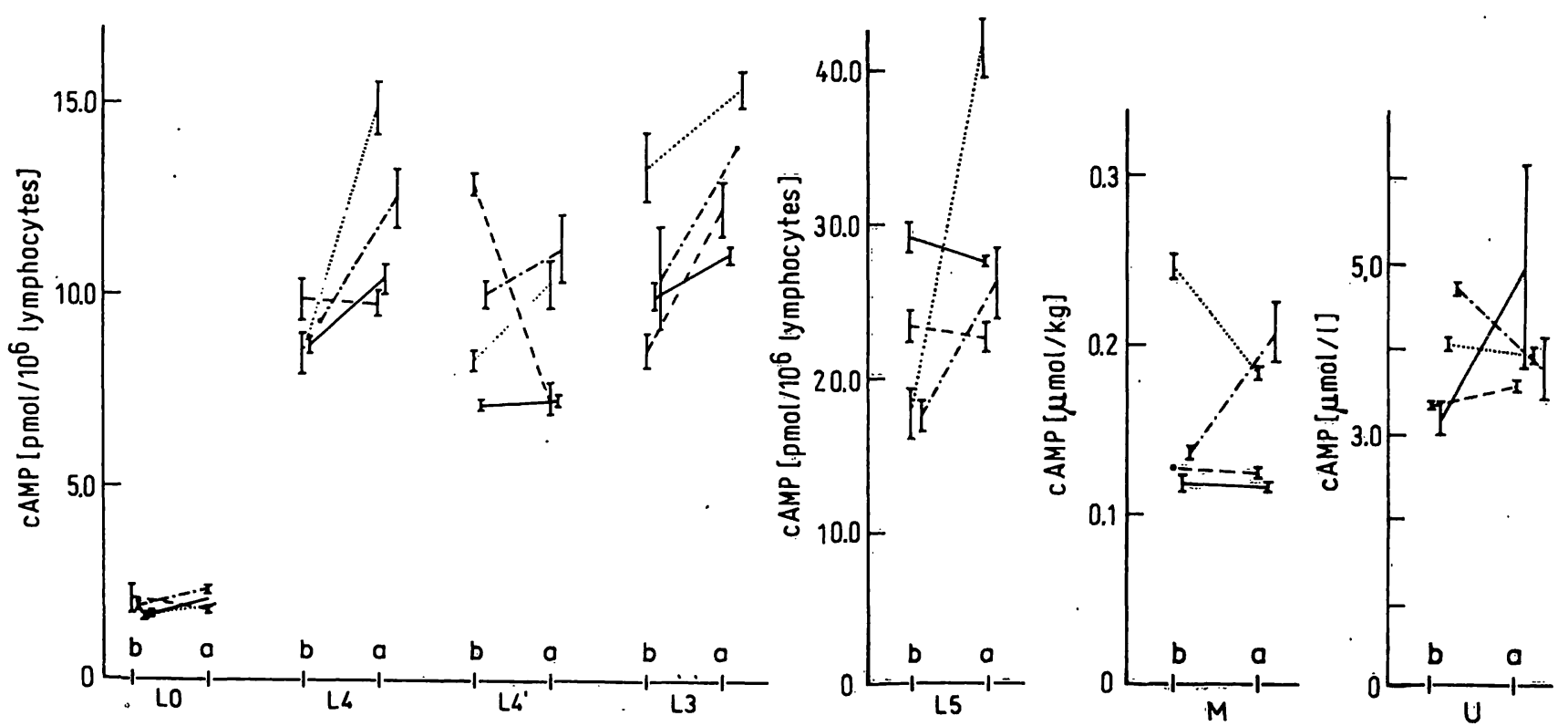

Fig. 1. The cAMP contents of the seven extracts measured with the four kits before and after purification. All values were measured four times (the mean value and the range are shown). They have been corrected for losses during the extraction and purification procedures by means of the internal standard. The values for the lymphocyte extracts (L0, L5, L4, L4, L L3) are expressed as pmol/106 lymphocytes; L4 and L4' are extracts from different samples. The cAMP content of the mammary tumour extract $(M)$ is expressed as $\mu \mathrm{mol} / \mathrm{kg}$ tissue and that of the urine $(U)$ as $\mu \mathrm{mol} / \mathrm{l}$.

$\mathrm{b}=$ before purification, $\mathrm{a}=$ after purification.

Kit A - - B C C.... D D ...... 


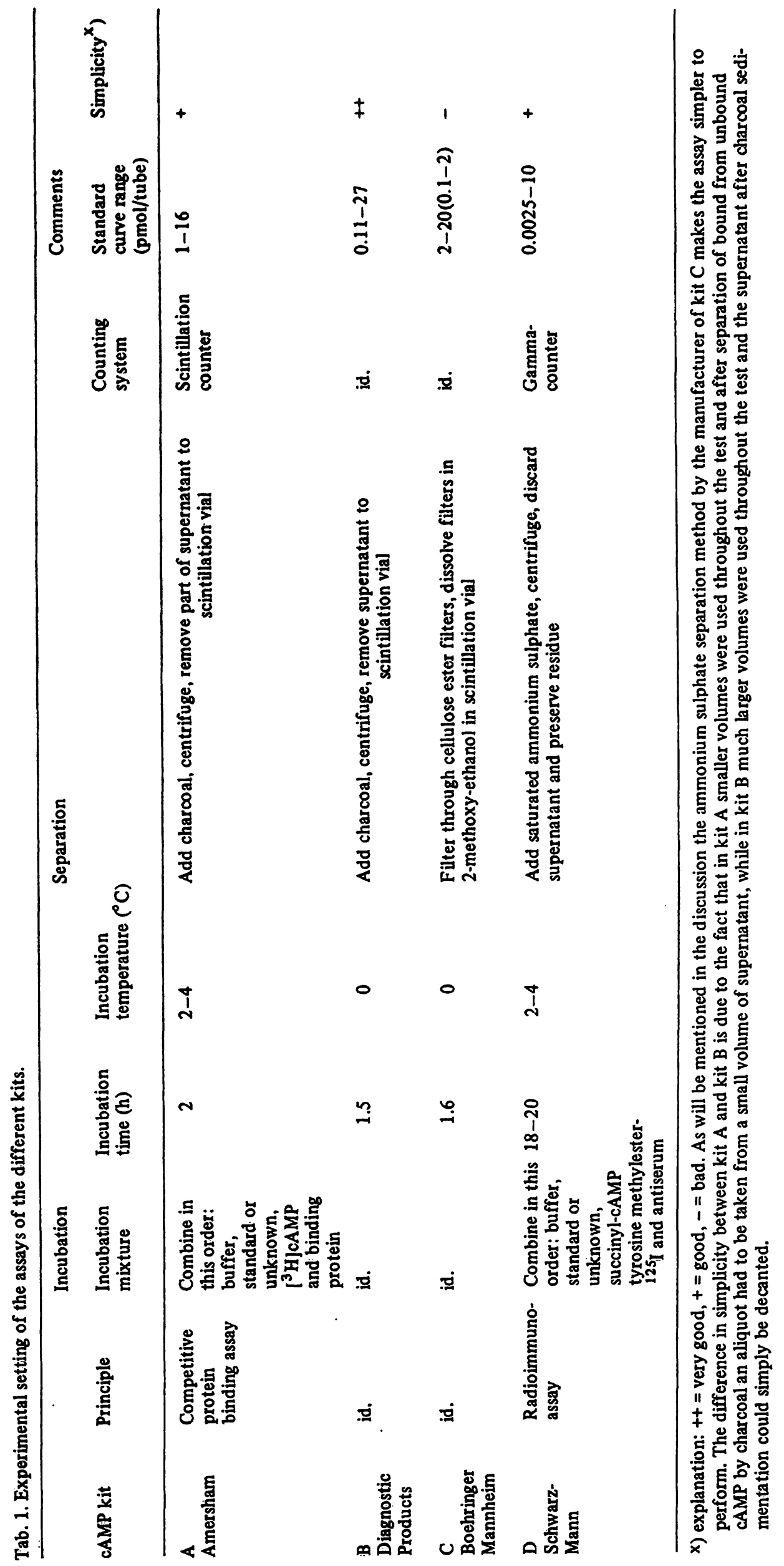




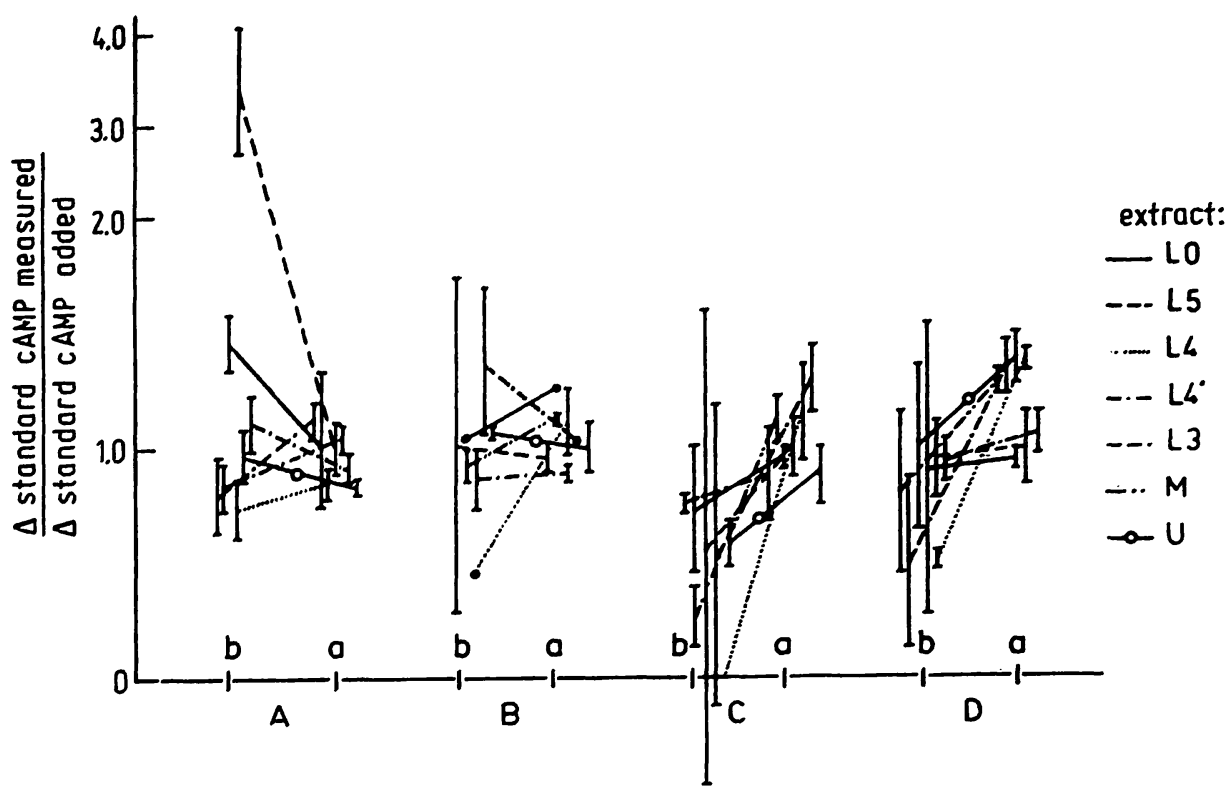

Fig. 2. Results of the addition experiments expressed as $\Delta$ standard cAMP measured/ $\Delta$ standard cAMP added (the mean value and the range are shown). The meaning of the symbols is the same as in figure 1.

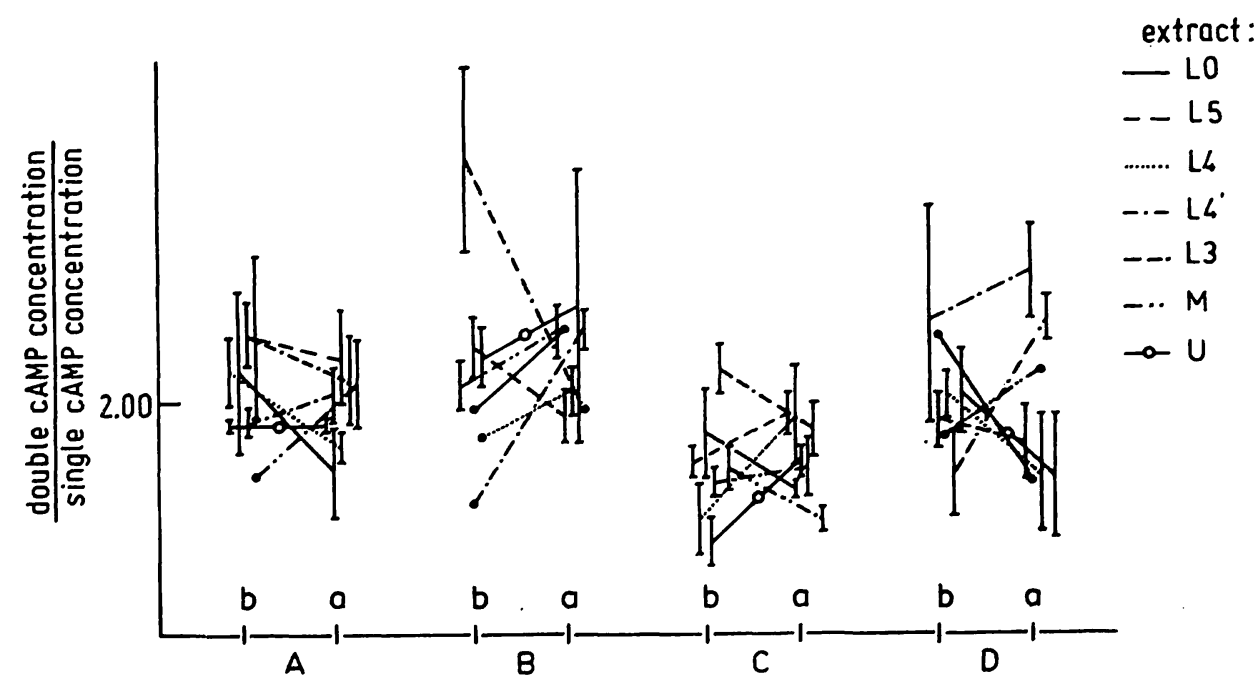

Fig. 3. Results of the double amount experiments expressed as the ratio of the double versus the single cAMP concentration (the mean value and the range are shown). The meaning of the symbols is the same as in figure 1.

To verify the identity of the substance measured with the different kits, a phosphodiesterase test was performed in extracts L5, LA, L3 and M. The test was applied to both unpurified and purified extracts. After phosphodiesterase treatment of the extracts, none of the kits detected a significant amount of cAMP, with the exception of extract $M$ before purification (the average amount CAMP not hydrolysed in this extract was $75 \%$ of the initial value).

Intra-assay variations for the four kits were $4.1 \%$ for kit A, $5.5 \%$ for B, $7.4 \%$ for $C$ and $14.5 \%$ for D. No attempt was made to determine the interassay variation.

\section{Discussion}

The cAMP values found in the lymphocytes and in the urine are in accordance with those in the literature $(7,8$, $10,11,12)$. The cAMP content in the mammary cancer tissue extract is about twenty-fold lower than found by Minton et al (13) and about four times lower than reported by Guerinot \& Bohuon (14), presumably because the tissue was not immediately frozen in liquid nitrogen after surgical removal of the tumour.

The incomplete hydrolysis of cAMP in the unpurified extract $M$ was probably caused by an inhibitor of the phosphodiesterase, which was removed by purification. 


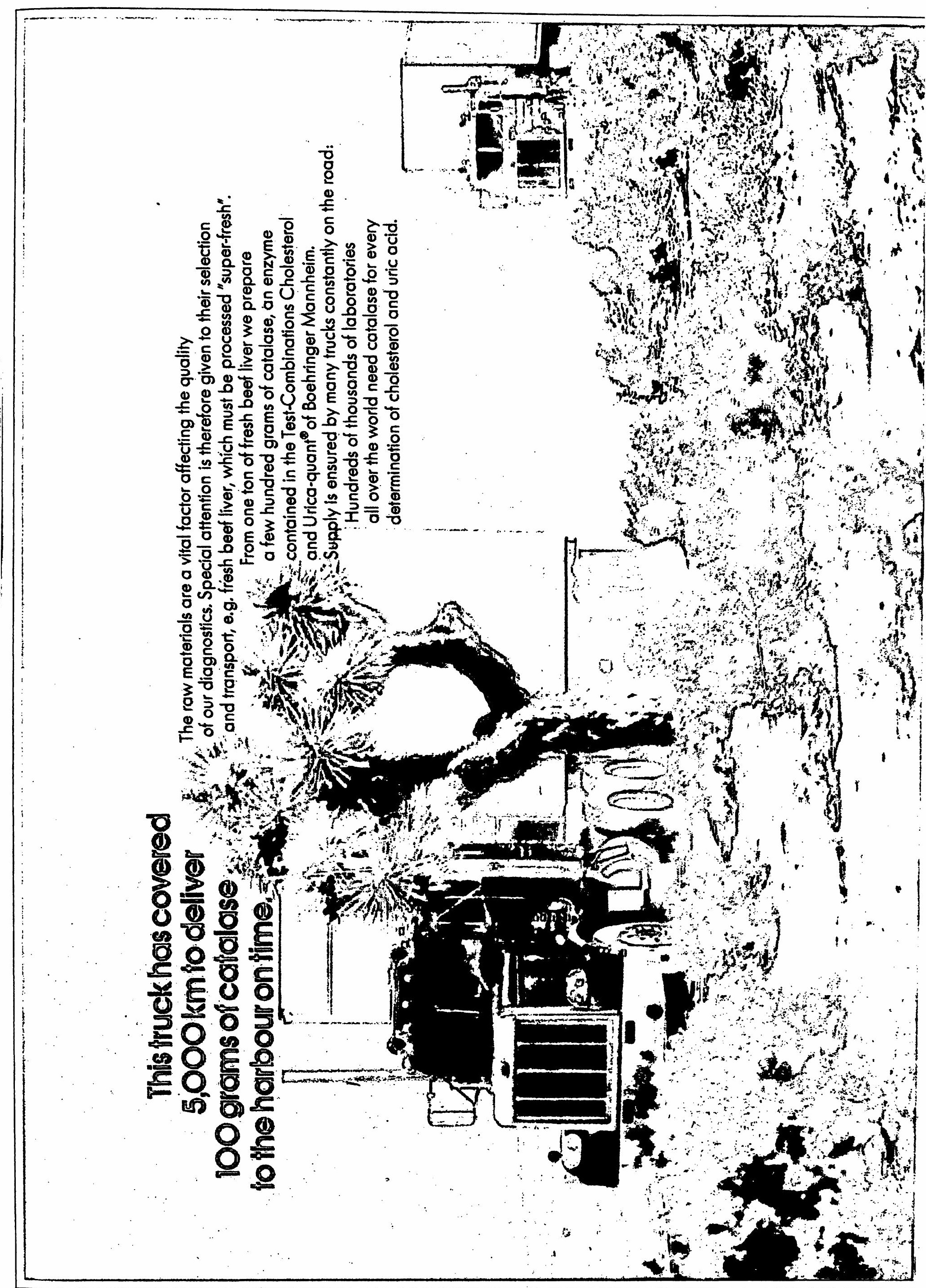




\section{H. Ch. Curtius A. Roth (Editors)}

\section{Clinical Biochemistry \\ Principles and Methods}

2 volumes. Paperback edition 1978.

$15,5 \mathrm{~cm} \times 23,0 \mathrm{~cm}$. With numerous tables and figures.

Volume I: LXIII, pages 1-854.

DM 105,-; \$49.50 ISBN 3110076691

Volume II: LXIII, pages 855-1677.

DM 105,-; \$49.50 ISBN 3110076705

61 authors from 11 different countries have contributed to this book which presents many of the techniques of interest to clinical chemists and clinical biochemists.

Current procedures are critically discussed, and special emphasis is given to new methods likely to become important in the coming years. A number of techniques are given in detail, and the others are presented with the appropriate references.

The book contains numerous tables and illustrations, and an extensive index permits ready access to specific items.

Prices are suḅject to change without notice 
This explanation is based on the observation that the cAMP contents measured in this extract before and after purification showed no significant differences.

The results shown above demonstrate that the analytical properties of the four kits are different. In our opinion, the order of the reliability of the different kits is: $A=$ B $>$ D $>$ C. Apart from this, other factors are important for the final appreciation of the different kits, which are listed in table 1 under comments.

A remarkable difference between the kits is the range over which cAMP can be measured. Important factors that determine the characteristics of an assay system are the specific activity of the label, the amount of label added, the amount of binding protein or anti-serum added, the dissociation constants of these proteins and the final volume of the incubation mix ture $(15,16)$. Because we did not measure the kinetic properties of the binding proteins and the anti-serum, a complete analysis of the characteristics of the kits in terms of the choice of the amount and quality of the reagents used is not possible. The assay system of kit $A$ and the (freedom from) interference by non-specific materials has been fully described by Tovey et al (17).

During the time this paper was in preparation kit $C$ was modified in two ways. Firstly, instead of the filtration step, an ammonium sulphate precipitation was introduced to separate bound from free cAMP, which simplifies the performance of the assay. Secondly, to stabilize the binding protein an immuno globulin (IgG) was added. The high sensitivity $(0.1-2 \mathrm{pmol} /$ tube $)$ claimed by the manufacturer for the unmodified kit could only be reached if the kit was used directly within a month, long before the stated expiration time (personal communication). Thereafter the slope of the standard curve gradually diminished. The stabilisation of the binding protein might have improved the kit in this respect.

Furthermore, a modification in the radioimmunoassay of cAMP originally developed by Harper \& Brooker (18) was recently introduced commercially (New England Nuclear). This makes it possible to measure even smaller amounts of CAMP (0.0025-0.50 pmol/tube); before being assayed the CAMP (from extract and standard preparation) is first acetylated.

In conclusion we would like to emphasize that it is not possible to recommend a particular kit, because the choice to be made depends on the demands of the investigator, which, of course, may vary. However, in our opinion the unmodified kit $\mathrm{C}$ was inferior to the others. On the basis of our investigation we have decided to use kit B.

\section{Acknowledgements}

The authors wish to thank Dr. $R$. van Wijk from the Department of Molecular Biology, State University Utrecht, for many helpful discussions.

\section{References}

1. Sutherland, E. W. \& Rall, T. W. (1958), J. Biol. Chem. 232, 1077-1091.

2. Jost, J. P. \& Rickenberg, H. V. (1972), Ann. Rev. Biochem. $1,95-148$.

3. Gilman, A. G. (1970), Proc. Nat. Acad. Sci. USA 67, 305312.

4. Steiner, A. L., Kipnis, D. M., Utiger, R. \& Parker, C. (1969), Proc. Nat. Acad. Sci. USA 64, 367-373.

5. Paladani, A. C. \& Leloir, L. F. (1952), Biochem. J. 51, 426430.

6. Bфyum, A. (1968), Scand. J. Clin. Lab. Invest. 21, suppl.97, $77-89$.

7. Gillèpsie, E., Valentine, M. P. \& Lichtenstein, L. M. (1974),

J. Allerg. Clin. Immunol. 53, 27-33.

8. Gilman, A. G. (1972), Adv. Cyclic Nucleotide Res. 2, 9-24.

9. Mao, C. C. \& Guidotti, A. (1974), Anal. Biochem. 59, 63-68.

10. Steiner, A. L., Wehmann, R. E., Parker, C. W. \& Kipnis, D. M. (1972), Adv. Cyclic Nucleotide Res. 2, 51-61.
11. Steiner, A. L., Pagliara, A. S., Chase, L. R. \& Kipnis, D. M. (1972), J. Biol. Chem. 247, 1114-1120.

12. Pak, C.Y.C., Ohata, M., Lawrence, E.C. \& Snyder, W. (1974), J. Clin. Invest. 54, 387-400.

13. Minton, J. P., Wisenbaugh, T. \& Matthews, R. M. (1974), J. Nat. Cancer Inst. 53, 283-284.

14. Guerinot, F. \& Bohuon, G. Abstract Semaine Scientifique Internationale de Tours 28 Septembre-2 Octobre 1976.

15. Ekins, R. \& Newman, B. (1970), in Karolinska Symposia on Research Methods in Reproductive Endocrinology (Diszfalusy, E., ed.), p. 11, Bogtrykkeriet Forum, Copenhagen.

16. Brown, B. L., Ekins, R. P. \& Albano, J. D. M. (1972), Adv. Cyclic Nucleotide Res. 2, 25-40.

17. Tovey, K. C., Oldham, K. G. \& Whelan, J. A. M. (1974), Clin. Chim. Acta 56, 221-234.

18. Harper, J. F. \& Brooker, G. (1975), J. Cyclic Nucleotide Res. $1,207-218$.
J. Vossenberg, $\mathrm{Ph}$. D. Department of Endocrinology Academic Hospital Catharijnesingel 101 NL-UTRECHT 
